\title{
Numerical Study of Fluid Dynamic and Heat Transfer in a Compact Heat Exchanger Using Nanofluids
}

\author{
P. Gunnasegaran, N. H. Shuaib, M. F. Abdul Jalal, and E. Sandhita \\ Department of Mechanical Engineering, College of Engineering, Universiti Tenaga Nasional, Km7, Jalan Kajang-Puchong, \\ 43009 Kajang, Malaysia
}

Correspondence should be addressed to N. H. Shuaib, hafeez@uniten.edu.my

Received 5 November 2011; Accepted 19 December 2011

Academic Editors: S. W. Chang, A. E. Huespe, K. Y. Suh, and B. Yu

Copyright ( $\odot 2012$ P. Gunnasegaran et al. This is an open access article distributed under the Creative Commons Attribution License, which permits unrestricted use, distribution, and reproduction in any medium, provided the original work is properly cited.

Compact heat exchangers (CHEs) are characterized by a high surface area per unit volume, which can result in a higher efficiency than conventional heat exchangers. They are widely used in various applications in thermal fluid systems including automotive thermal fluid systems such as radiators for engine cooling systems. Recent development of nanotechnology brings out a new heat transfer coolant called "nanofluids," which exhibit larger thermal properties than conventional coolants due to the presence of suspended nanosized composite particles in a base fluid. In this study, a numerical investigation using different types of nanoparticles in ethylene glycol-base fluid namely copper $(\mathrm{Cu})$, diamond $(\mathrm{DM})$, and silicon dioxide $\left(\mathrm{SiO}_{2}\right)$ on automobile flat tube plate-fin cross-flow CHE is explored. The nanoparticles volume fraction of $2 \%$ is considered for all types of nanofluids examined in this study. The three-dimensional (3D) governing equations for both liquid flow and heat transfer are solved using a standard finite volume method (FVM) for the range of Reynolds number between 4000 and 7000. The standard $\kappa-\varepsilon$ turbulence model with wall function is employed. The computational model is used to study the variations of shear stress, skin friction, and convective heat transfer coefficient. All parameters are found to yield higher magnitudes in the developing and developed regions along the flat tubes with the nanofluid flow than base fluid. The pressure drop is slightly larger for nanofluids but insignificant at outlet region of the tube. Hence, the usage of nanofluids in CHEs transfers more energy in a cost-effective manner than using conventional coolants.

\section{Introduction}

The new technological developments as well as the industrial process intensification have propelled the needs for more efficient heat-exchanging systems. In the recent years, the scientific research interest is focused both on improving the equipment design and on enhancing the thermal capability of the working fluids.

The progress in equipment design has led to the development of compact heat exchanger (CHE) with modulated surface. CHEs are characterized by a high surface area per unit volume, which can result in a higher efficiency than conventional heat exchangers (typically CHEs can achieve efficiencies of over $95 \%$ cf. $80 \%$ for noncompact heat exchangers for the same volume). Hence, CHEs are able to transfer more energy in a cost-effective manner than other types of heat exchangers and enable more energy saving when compared to standard technology [1]. CHEs have been widely used in automotive thermal fluid systems such as radiators or air coolers for engine cooling systems and as intercoolers in turbocharging systems.

In an automobile, combustion of fuel and air produces power within the engine. Only a portion of the total generated power actually supplies the automobile with power, and the rest is wasted in the form of exhaust and heat. A cooling system which contains a radiator is used to remove this excess heat. If this excess heat is not removed, the engine temperature becomes too high which can result in overheating and viscosity breakdown of the lubricating oil, metal weakening of the overheated engine parts, and stress between engine parts resulting in quicker wear, among others. As coolant travels through the engine's cylinder block, it accumulates 
heat. Once the coolant temperature increases above a certain threshold value, the vehicle's thermostat triggers a valve which forces the coolant to flow through the radiator. As the coolant flows through the tubes of the radiator, heat is transferred through the fins and tube walls to the air by conduction and convection.

However, inherently low thermal conductivity of the conventional coolants such as oil, water, and EG is a primary limitation in developing energy-efficient heat transfer fluids that are required for high-performance cooling. Thus, the conventional coolants are poor heat transfer fluids in nature, as the thermal conductivity of these fluids plays an important role on heat transfer coefficient between the heat transfer medium and the heat transfer surface. In recent years, numerous methods have been proposed to improve the thermal conductivity of these fluids by suspending nanoparticle materials with average sizes below $100 \mathrm{~nm}$ in liquids, which result in liquids which are called "nanofluids." Nanofluids, which are nanoparticle liquid suspensions, is the term coined by Choi [2] to describe this new class of nanotechnology-base heat transfer fluids that exhibit thermal properties superior to those of their conventional or base fluids. In [3], Trisaksri and Wongwises [4] and Wang and Mujumdar [5] have recently summarized the work done in this area. The available literature indicates that the thermal conductivity of the nanofluid is higher than that of the base fluid, and it depends strongly on the size, shape, and volume fraction of the nanoparticles as well as on the type of the nanoparticles and of the base fluid $[6,7]$.

Xie et al. [8] investigated experimentally the thermal conductivity behavior of nanometer-sized $\mathrm{Al}_{2} \mathrm{O}_{3}$ suspensions in water, oil, and EG. Their experimental results showed that the addition of nanoparticles into base fluids leads to increasing the thermal conductivities of the suspensions. The enhancement of thermal conductivity ratios increases with the volume fraction of nanoparticles. For the suspensions using the same nanoparticles, the enhanced thermal conductivity ratio is reduced with increasing thermal conductivity of the base fluid.

Eastman et al. [9] pointed out in their experimental work that nanofluid consisting of $\mathrm{Cu}$ nanometer-sized particles dispersed in EG has a much higher effective thermal conductivity than pure EG. The effective thermal conductivity of EG is found to be increased by up to $40 \%$ for a nanofluid consisting of EG containing approximately $0.3 \%$ of $\mathrm{Cu}$ nanoparticles compared to EG-base nanofluids containing either $\mathrm{CuO}$ or $\mathrm{Al}_{2} \mathrm{O}_{3}$ nanoparticles with the same particle volume fractions. They concluded that nanofluids consisting of $\mathrm{Cu}$ nanoparticles directly dispersed in EG have been observed to exhibit significantly improved thermal conductivity enhancements compared to nanofluids containing oxide particles. The large improvement in effective thermal conductivity obtained for nanofluids containing metallic particles holds significant potential for revolutionizing industries that are dependent on the performance of heat transfer fluids.

Leong et al. [10] investigated analytically the heat transfer characteristics of an automotive car radiator using EG-based $\mathrm{Cu}$ nanofluids as coolants. Relevant input data, nanofluid properties, and empirical correlations were obtained from literatures to investigate the heat transfer enhancement of an automotive car radiator operated with nanofluid. The results show that heat transfer coefficient and heat transfer rate in engine cooling system increased with the usage of nanofluids (with EG the base fluid) compared to EG (i.e., base fluid) alone. About 3.8\% of heat transfer enhancement could be achieved with the addition of $2 \% \mathrm{Cu}$ particles in a base fluid at the Reynolds numbers of 6000 and 5000 for air and coolant, respectively.

Farajollahi et al. [11] experimentally investigated the heat transfer characteristics such as convective heat transfer coefficient and Nusselt number of $\mathrm{Al}_{2} \mathrm{O}_{3}-\mathrm{H}_{2} \mathrm{O}$ and $\mathrm{TiO}_{2}-\mathrm{H}_{2} \mathrm{O}$ nanofluids for turbulent flow in a horizontal stainless steel shell and tube heat exchanger. The effects of Peclet number, volume concentration of suspended nanoparticles, and particle type on the heat transfer characteristics were investigated. Based on the results, adding of nanoparticles to the base fluid causes the significant enhancement of heat transfer characteristics. For both nanofluids, two different optimum nanoparticle concentrations exist. Comparison of the heat transfer behavior of two nanofluids indicates that at a certain Peclet number, heat transfer characteristics of $\mathrm{TiO}_{2}-\mathrm{H}_{2} \mathrm{O}$ nanofluid at its optimum nanoparticle concentration are greater than those of $\mathrm{Al}_{2} \mathrm{O}_{3}-\mathrm{H}_{2} \mathrm{O}$ nanofluid, while $\mathrm{Al}_{2} \mathrm{O}_{3}-\mathrm{H}_{2} \mathrm{O}$ nanofluid possesses better heat transfer behavior at higher nanoparticle concentrations.

A three-dimensional laminar flow and heat transfer of two different nanofluids, $\mathrm{Al}_{2} \mathrm{O}_{3}$ and $\mathrm{CuO}$, in an $\mathrm{EG}$ and water mixture circulating through the flat tubes of an automobile radiator were numerically studied by Vajjha et al. [12]. The objective of the study was to evaluate the superiority of nanofluid over the base fluid. New correlations for viscosity and thermal conductivity of nanofluids as a function of particle volumetric concentration and temperature developed from experiments were used in this paper. The results showed marked improvement of the convective heat transfer coefficient in the developing and developed regions along the flat tubes with the nanofluid compared to the base fluid. Results for the local and the average friction factor and convective heat transfer coefficient showed an increase with increasing particle volumetric concentration of the nanofluids. Quantitative results on the increase of the heat transfer coefficient and the friction factor with increasing volumetric concentrations of nanofluids at various Reynolds numbers are presented. The pressure loss was found to increase with increasing particle volumetric concentrations of nanofluids. However, due to the reduced volumetric flow needed for the same amount of heat transfer, the required pumping power diminishes.

Charyulu et al. [13] developed a mathematical model to predict the heat transfer and pressure drop in a radiator of a turbo-charged diesel engine. The study examined the effect of different materials of construction of fins and tubes, say, copper, brass, aluminum, carbon steel, and stainless steel by assuming that the bonding efficiency between tubes and fins is $100 \%$. The performance evaluation was carried out for various combinations of different materials for fins and tubes under normal operating conditions of the radiator. It was observed that there was an excess of the heat transfer of 
the order of 30\%, while using copper fins with copper tubes, brass tubes, and carbon steel tubes. Aluminum material for fins and tubes showed an excess of $28 \%$ in heat transfer. Also, with carbon steel for fins and tubes, this excess was reduced to $13 \%$. However, the stainless steel material for fins and tubes did not meet the requirement for a given set of parameters. The system parameters should, therefore, be selected very carefully when stainless steel is selected. Based on their observations, it is clear that the selection of fin material is very important. It was also observed that the copper fins with copper, brass, and carbon steel tubes offer the same heat transfer and pressure drop characteristics. Therefore, the designer should look into the mechanical properties of these materials suiting the requirement of the radiator.

Performance of $4 \% \mathrm{CuO}$ suspension in water as a coolant in a commercial herringbone-type plate heat exchanger (PHE) is experimentally studied by Pantzali et al. [14]. Their experimental results concerning the use of nanofluids in a commercial heat exchanger confirmed that, besides the physical properties, the type of flow (laminar or turbulent) inside the heat-exchanging equipment plays an important role in the effectiveness of a nanofluid. When the heat-exchanging equipment operates under conditions that promote turbulence, the use of nanofluids is beneficial if and only if the increase in their thermal conductivity is accompanied by a marginal increase in viscosity. On the other hand, if the heat exchanger operates under laminar conditions, the use of nanofluids seems advantageous, and the only disadvantage so far being their potential instability of the suspension.

Maiga et al. [15] studied $\mathrm{Al}_{2} \mathrm{O}_{3}$ nanofluid flow under forced laminar convection in circular tubes and between parallel disks. For a range of Reynolds numbers from 250 to 1000 , they concluded that the heat transfer enhancement is much more pronounced with an increase in particle concentration. However, they observed an adverse effect on wall shear stress in comparison to the base fluid. For the analysis of flow between discs, they found an insignificant effect on heat transfer with the variation of gap between the disks. A theoretical analysis was carried out with $\varepsilon$-NTU rating method by Vasu et al. [16] using $\mathrm{Al}_{2} \mathrm{O}_{3}+\mathrm{H}_{2} \mathrm{O}$ nanofluid as coolant on automobile flat tube plate-fin CHE. They observed that cooling capacity $\mathrm{Al}_{2} \mathrm{O}_{3}-\mathrm{H}_{2} \mathrm{O}$ nanofluid was very high compared to conventional fluid (pure water). The results indicated that with the increase of the volume fraction of the nanoparticle concentration, the cooling capacity increases in moderate manner, and the pressure drop decreases with coolant inlet temperature, but cooling capacity is very high when compared with $0 \%$ volume fraction (pure water).

It must be pointed out that the increase of thermal conductivity of nanofluids is necessary but not a sufficient condition to achieve high performance in heat-exchanging equipment. This study attempts to investigate the fluid flow and heat transfer characteristics of a CHE using EG based on different types of nanoparticles including $\mathrm{Cu}$, diamond (DM), and $\mathrm{SiO}_{2}$ as coolants, since it is known that the superior of thermophysical properties of the nanofluid depends strongly on the type of the nanoparticles. Thermal and hydraulic performance of the plate-fin cross-flow CHE operated with nanofluids is compared with that of using
TABLE 1: Core geometry of flat tubes, continuous fins, and operating conditions of a CHE.

\begin{tabular}{lcc}
\hline Serial number & Description & Dimension \\
\hline 1 & CHE height $(\mathrm{CHEh})$ & $0.0285 \mathrm{~m}$ \\
2 & CHE length $(\mathrm{CHEl})$ & $0.095 \mathrm{~m}$ \\
3 & CHE width $(\mathrm{CHEw})$ & $0.025 \mathrm{~m}$ \\
4 & Tube height $(\mathrm{tH})$ & $0.0013 \mathrm{~m}$ \\
5 & Tube length $(\mathrm{tL})$ & $0.0948 \mathrm{~m}$ \\
6 & Tube width $(\mathrm{tW})$ & $0.0248 \mathrm{~m}$ \\
7 & Fin height $(\mathrm{fH})$ & $0.012 \mathrm{~m}$ \\
8 & Fin width $(\mathrm{fW})$ & $0.025 \mathrm{~m}$ \\
9 & Fin thickness $(\mathrm{fT})$ & $0.0001 \mathrm{~m}$ \\
10 & Distance between fins $(\mathrm{fD})$ & $0.0018 \mathrm{~m}$ \\
11 & Number of tubes $(n$ tube) & 3 \\
12 & Number of fins $(n$ fin $)$ & 25 \\
13 & Air side hydraulic diameter, $D_{h}$ & $0.00267 \mathrm{~m}$ \\
14 & Coolant side hydraulic diameter, $D_{h}$ & $0.00283 \mathrm{~m}$ \\
15 & Air temperature $\left(T_{a}\right)$ & $310.5 \mathrm{~K}$ \\
16 & Coolant temperature $\left(T_{c}\right)$ & $355.5 \mathrm{~K}$ \\
\hline
\end{tabular}

conventional coolant. Results of interests such as heat transfer coefficient variation, shear stress, skin friction, pressure drop, and pumping power as function of Reynolds number are reported to illustrate the effects of using different types of nanofluids on these parameters. The results from this study can be used in the design process of more efficient and reliable CHEs.

\section{Problem Description and Governing Equations}

2.1. CHE Model. The directions of the coolant and air flows cross each other are shown in Figure 1(a). The geometry of the problem analyzed in this study is a flattened tube for the coolant flow and plate fins for the air flow, as illustrated in Figures 1(b) and 1(c), respectively. As described by Frass [17], the aerodynamically shaped fins and flattened tubes give close to the best performance obtainable. When compared with a circular tube, the flat tube has a relatively smaller pressure drop on the air side with the increased heat transfer area. The specified dimensions of the present CHE are given in Table 1.

\subsection{Thermophysical Properties of Nanofluids and Nanofluids} Model. The thermophysical properties of all types of nanofluids as coolants with a particle volume fraction of $2 \%$ and air are listed in Tables 2 and 3, respectively. For all types of nanofluids, the density, thermal conductivity, and dynamic viscosity appear significantly higher, while the specific heat of nanofluids is lower than the base fluid. For an instance, the EG-DM nanofluid has a relative increase of $4.52 \%, 6.13 \%$, and $5.01 \%$ in the density, thermal conductivity, and dynamic viscosity and has a relative decrease of $5.08 \%$ in specific heat, 


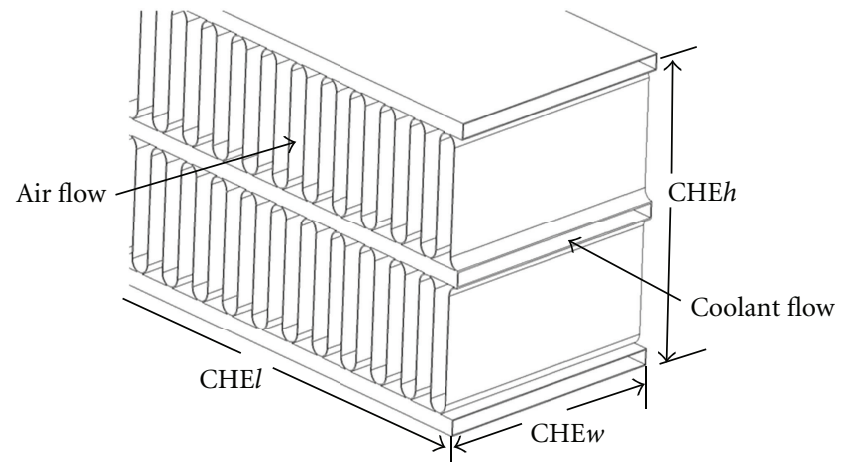

(a)

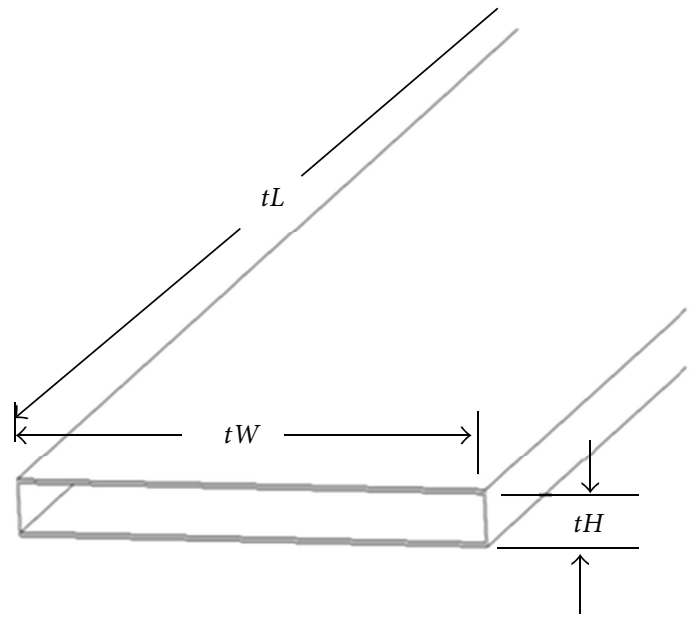

(b)

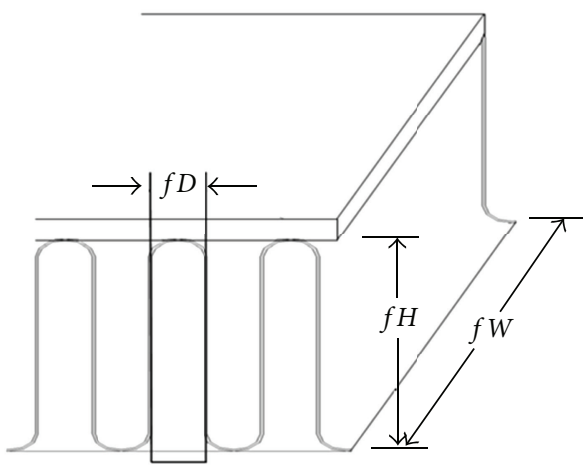

(c)

Figure 1: (a) Expanded view of the CHE core. (b) Expanded view of the tubes. (c) Expanded view of the fins.

TABLE 2: Thermophysical properties of coolants [26].

\begin{tabular}{|c|c|c|c|}
\hline Properties & $\begin{array}{l}\text { Nanoparticle } \\
\text { (diamond) }\end{array}$ & $\begin{array}{l}\text { Base fluid } \\
\text { (ethylene glycol) }\end{array}$ & $\begin{array}{c}\text { Nano fluid (DM-EG) } \\
\qquad \varphi=2 \%\end{array}$ \\
\hline$\rho\left(\mathrm{kg} / \mathrm{m}^{3}\right)$ & 3510 & 1076 & 1124.68 \\
\hline$C_{p}(\mathrm{~J} / \mathrm{kg} \cdot \mathrm{K})$ & 497.26 & 2664 & 2528.76 \\
\hline$\kappa(\mathrm{W} / \mathrm{m} \cdot \mathrm{K})$ & 1000 & 0.261 & 0.277 \\
\hline$\mu\left(\mathrm{Ns} / \mathrm{m}^{2}\right)$ & & 0.003036 & 0.003188 \\
\hline Properties & $\begin{array}{l}\text { Nanoparticle } \\
\text { (silicon dioxide) }\end{array}$ & $\begin{array}{l}\text { Base fluid } \\
\text { (ethylene glycol) }\end{array}$ & $\begin{array}{c}\text { Nano fluid }\left(\mathrm{SiO}_{2}-\mathrm{EG}\right) \\
\varphi=2 \%\end{array}$ \\
\hline$\rho\left(\mathrm{kg} / \mathrm{m}^{3}\right)$ & 2200 & 1076 & 1098.48 \\
\hline$C_{p}(\mathrm{~J} / \mathrm{kg} \cdot \mathrm{K})$ & 703 & 2664 & 2528.45 \\
\hline$\kappa(\mathrm{W} / \mathrm{m} \cdot \mathrm{K})$ & 1.2 & 0.261 & 0.2696 \\
\hline$\mu\left(\mathrm{Ns} / \mathrm{m}^{2}\right)$ & & 0.003036 & 0.003188 \\
\hline Properties & $\begin{array}{l}\text { Nanoparticle } \\
\text { (copper) }\end{array}$ & $\begin{array}{l}\text { Base fluid } \\
\text { (ethylene glycol) }\end{array}$ & $\begin{array}{c}\text { Nano fluid (Cu-EG) } \\
\varphi=2 \%\end{array}$ \\
\hline$\rho\left(\mathrm{kg} / \mathrm{m}^{3}\right)$ & 8933 & 1076 & 1233.14 \\
\hline$C_{p}(\mathrm{~J} / \mathrm{kg} \cdot \mathrm{K})$ & 385 & 2664 & 2333.81 \\
\hline$\kappa(\mathrm{W} / \mathrm{m} \cdot \mathrm{K})$ & 401 & 0.261 & 0.2769 \\
\hline$\mu\left(\mathrm{Ns} / \mathrm{m}^{2}\right)$ & & 0.003036 & 0.003188 \\
\hline
\end{tabular}


TABLE 3: Thermophysical properties of air [26].

\begin{tabular}{lc}
\hline Air properties & \\
\hline$\rho\left(\mathrm{kg} / \mathrm{m}^{3}\right)$ & 1.225 \\
$C_{p}(\mathrm{~J} / \mathrm{kg} \cdot \mathrm{K})$ & 1006.43 \\
$\kappa(\mathrm{W} / \mathrm{m} \cdot \mathrm{K})$ & 0.0242 \\
$\mu\left(\mathrm{Ns} / \mathrm{m}^{2}\right)$ & 0.000017894 \\
\hline
\end{tabular}

respectively, compared with EG-base fluid. The thermophysical properties of required nanofluids for flow in a CHE as listed in Table 2 are calculated using the following equations [18-21], accordingly

density:

$$
\rho_{n f}=(1-\varphi) \rho_{b f}+\varphi \rho_{p}
$$

heat capacity:

$$
\left(\rho c_{p}\right)_{n f}=(1-\varphi)\left(\rho c_{p}\right)_{b f}+\varphi\left(\rho c_{p}\right)_{p},
$$

thermal conductivity:

$$
k_{n f}=\frac{k_{p}+2 k_{b f}+2\left(k_{p}-k_{b f}\right) \varphi}{k_{p}+2 k_{b f}-\left(k_{p}-k_{b f}\right) \varphi} k_{b f},
$$

viscosity:

$$
\mu_{n f}=\mu_{b f}(1+2.5 \varphi),
$$

where $\varphi$ is particle volume fraction, the subscript " $n f$ " refers to nanofluid, " $b f$ " refers to base fluid, and " $p$ " refers to particle.

Many recent studies have shown that the low particle volumetric concentration of the nanoparticles in the base fluid makes it behave like a single-phase fluid [15, 22]. Lee and Mudawar [23] suggested that nanoparticles should not be used in two-phase CHE. This is because once boiling commences, particles begin to deposit into relatively large clusters near the tube exit due to localized evaporation. This clustering phenomenon quickly propagates upstream to fill the entire tube, preventing coolant from entering the CHE and causing catastrophic failure of the cooling system. Thus, the nanofluid is assumed to behave as a single-phase fluid. Thus, all the governing equations of mass, momentum, and energy can be applied to nanofluids, as in the case of pure fluids, by changing the appropriate thermophysical properties as listed in Table 2.

2.3. Governing Equations. The problem under investigation is a three-dimensional steady and forced turbulent convection flow of nanofluid flowing inside a flat tube having width of $0.025 \mathrm{~m}$, height of $0.012 \mathrm{~m}$, and length of $0.0948 \mathrm{~m}$. The nanofluid is assumed to be in single phase, incompressibleing and enter the flat tube with uniform axial velocity and temperature. The properties of both nanofluid and CHE material are temperature independent. All the surfaces of CHE exposed to the surroundings are assumed to be insulated.
The governing equations for the fluid flow are [24]

$$
\begin{gathered}
\operatorname{div}(\rho \bar{V})=0 \\
\operatorname{div}(\rho \bar{V} \bar{V})=-\operatorname{grad}(\bar{P})+\mu \nabla^{2} \bar{V}-\operatorname{div}\left(\rho \overline{u^{\prime} u^{\prime}}\right) \\
\operatorname{div}\left(\rho \bar{V} c_{p} \bar{T}\right)=\operatorname{div}\left(k \operatorname{grad} \bar{T}-\rho c_{p} \overline{u^{\prime} t^{\prime}}\right) .
\end{gathered}
$$

In the above equations, the symbols $\bar{V}, \bar{P}$, and $\bar{T}$ represent the time-averaged flow variables, while the symbols $u^{\prime}$ and $t^{\prime}$ represent the fluctuations in velocity and temperature. The terms in the governing equations $\rho \overline{u^{\prime} u^{\prime}}$ and $\rho c_{p} \overline{u^{\prime} t^{\prime}}$ represent the turbulent shear stress and turbulent heat flux. These terms are unknown and must be approximately expressed in terms of mean velocity and temperature.

2.4. Boundary Conditions. The governing equations of the fluid flow are nonlinear and coupled partial differential equations, subjected to the following boundary conditions. At the inlet of the flat tube and fin, uniform axial velocity and temperature are prescribed. In current simulations, following Park and Pak [25], the inlet velocity determines the Reynolds number of the flow. The Reynolds number considered in this study was varied from 4000 to 6000 for air and from 5000 to 7000 for coolant. The inlet velocity for both coolant and air are specified and calculated using [26]

$$
u_{\text {in }}=\frac{\operatorname{Re} \mu}{\rho D_{h}} .
$$

The inlet temperature of coolant and air has been taken as $82.5^{\circ} \mathrm{C}(355.5 \mathrm{~K})$ and $37.5^{\circ} \mathrm{C}(310.5 \mathrm{~K})$, respectively, which is typical for automotive CHE. All along the fin and tube wall, a no-slip boundary condition is imposed for velocity. Pressure outlet boundary condition has been implemented for the outlet section.

2.5. Numerical Solution Using FVM. The governing conservation equations (2)-(4) with the corresponding boundary conditions and equations for solid and fluid phases are simultaneously solved as a single-domain conjugate problem using the finite volume method (FVM) with a hybrid differencing scheme [27]. The standard SIMPLE algorithm is used as the computational algorithm [24]. The iterations continued until the sum of residuals for all computational cells became negligible (less than $10-7$ ), and velocity components did not change from iteration to iteration. Because of the assumption of constant fluid properties and negligible buoyancy, the mass and momentum equations were not coupled to the energy equation. Therefore, the temperature field was calculated by solving the energy equation after a converged solution for the flow field was obtained by solving the momentum and continuity equations.

2.6. Turbulence Modeling. In the present numerical analysis, the standard $\kappa-\varepsilon$ turbulent model proposed by Launder and Spalding [28] was adopted. The reason for using 


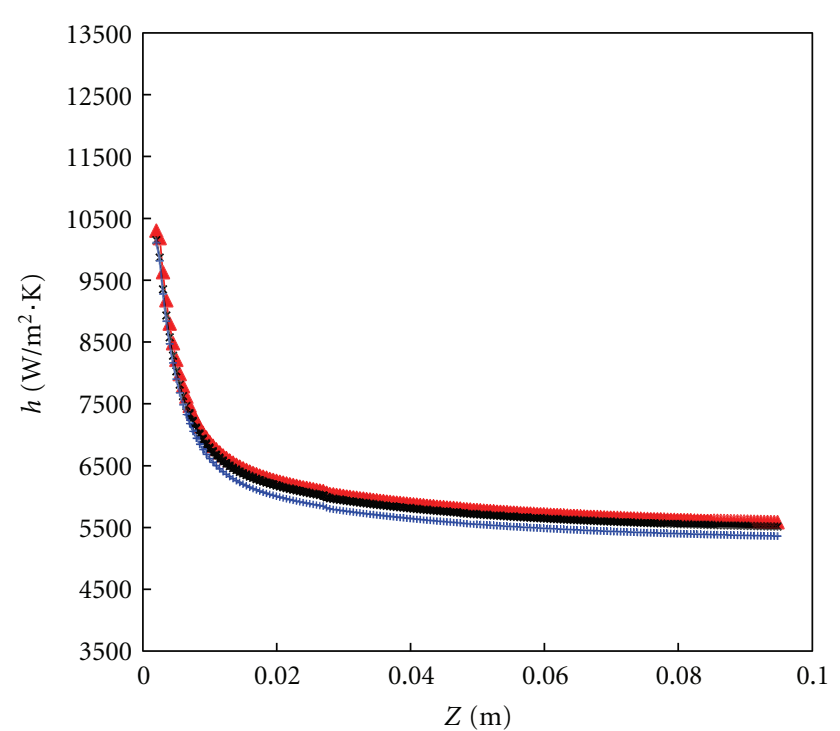

$\triangle 2.5 \times 10^{6}$ grids
$+\quad 1.9 \times 10^{6}$ grids
$+\quad 1.1 \times 10^{6}$ grids

FIGURE 2: Variation of heat transfer coefficient along the tube length for three different computational grids.

$\kappa-\varepsilon$ turbulent model in the current study is because this model performs very well in confined flows or channelized flow which is suitable for the current geometry and range of Reynolds number used. $\kappa-\varepsilon$ is the most widely validated turbulence model [28]. In brief, $\kappa-\varepsilon$ turbulent model introduces two additional equations, namely, turbulent kinetic energy $(\kappa)$ and rate of dissipation $(\varepsilon)$.

The equations for turbulent kinetic energy $(\kappa)$ and rate of dissipation $(\varepsilon)$ are given by

$$
\begin{aligned}
\operatorname{div}(\rho \bar{V} \kappa)= & \operatorname{div}\left\{\frac{\left(\mu+\mu_{t}\right)}{\sigma_{\kappa}} \operatorname{grad} \kappa\right\}+G_{\kappa}-\rho \varepsilon, \\
\operatorname{div}(\rho \bar{V} \varepsilon)= & \operatorname{div}\left\{\left[\mu+\left(\frac{\mu_{t}}{\sigma_{\varepsilon}}\right)\right] \operatorname{grad} \varepsilon\right\}+C_{1 \varepsilon}\left(\frac{\varepsilon}{\kappa}\right) G_{\kappa} \\
& +C_{2 \varepsilon} \rho\left(\frac{\varepsilon^{2}}{\kappa}\right) .
\end{aligned}
$$

In the above equations, $G_{\kappa}$ represents the generation of turbulent kinetic energy due to mean velocity gradients, $\sigma_{\kappa}$ and $\sigma_{\varepsilon}$ are effective Prandtl numbers for turbulent kinetic energy and rate of dissipation, respectively, $C_{1 \varepsilon}$ and $C_{2 \varepsilon}$ are constants, and $\mu_{t}$ is the eddy viscosity and is modeled as

$$
\mu_{t}=\frac{\left(\rho C_{\mu} \kappa^{2}\right)}{\varepsilon}
$$

where $C_{\mu}$ is a constant and its value is 0.09 .

In (5) and (6), $C_{1 \varepsilon}=1.44, C_{2 \varepsilon}=1.92, \sigma_{\kappa}=1.0$, and $\sigma_{\varepsilon}=$ 1.3. Further information is available in [28] for turbulence modeling.

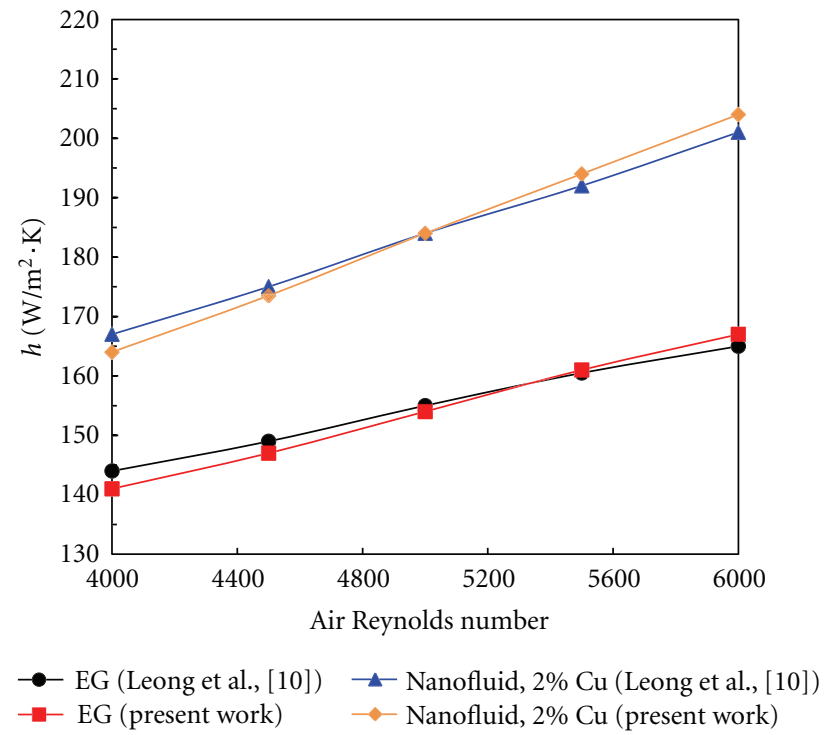

FIGURE 3: Comparison of the present numerical results with the theoretical results from Leong et al. [10] for average air heat transfer coefficient against the air Reynolds number.

\section{Numerical Results, Grid Testing, and Code Validation}

A three-dimensional mesh is generated for the numerical simulations, and an extensive mesh testing was performed to guarantee grid-independent solutions. Different grid densities of $1.1 \times 10^{6}, 1.9 \times 10^{6}$, and $2.5 \times 10^{6}$ are generated and used in a grid independence test. In Figure 2, the convective heat transfer coefficient along the length of the tube using $\mathrm{EG}$ as a coolant is shown using three grid systems under $\mathrm{Re}=$ 5000. Based on the results shown in Figure 2, it is seen that the heat transfer coefficient obtained for computational cells with $1.1 \times 10^{6}$ grid does not match with the results obtained for the other two higher number grids. Results of $1.9 \times 10^{6}$ and $2.5 \times 10^{6}$ grids overlap one another. Therefore, it was concluded that the grid number of $1.9 \times 10^{6}$ ensures a gridindependent solution, and this mesh is used for all analysis in this study.

To validate the present computational model, the comparison of present results with data available from Leong et al. [10] is presented in Figure 3, which shows the air heat transfer coefficient versus Reynolds number. The air heat transfer coefficient obtained from the present study has been computed using pure EG and EG-based copper $(\mathrm{Cu})$ nanofluids with $2 \%$ particle volume fraction. The air Reynolds number is varied from 4000 to 6000 , while coolant Reynolds number is fixed at 5000. As shown in Figure 3, the comparison between the present results and data of Leong et al. [10] is generally good. From the study, air heat transfer coefficient is found to increase linearly with the air Reynolds number.

\section{Results and Discussion}

4.1. Convective Heat Transfer of Nanofluids. The thermal performance of using different types of nanofluids in a CHE 
is examined by presenting the variation of the heat transfer coefficient along the tube length as shown in Figure 4. Since the velocity at the entrance of the tube was kept constant at $\operatorname{Re}=6000$ and the thermal boundary layer's thickness is zero at the entrance of the tube, the convection coefficient is extremely large at $Z=0 \mathrm{~m}$. However, the convective heat transfer coefficient reduces in bulk, until the constant values associated with the fully developed conditions are reached [26]. The present results show a similar trend with the results obtained by Vajjha et al. [12]. As depicted in Figure 4, it is noted that the difference in convective heat transfer coefficient between various nanofluids is rather small. However, it should be mentioned that all types of nanofluids-cooled CHE could be able to enhance the heat transfer compared to pure EG-cooled CHE. The EG-base nanofluid containing DM has the highest heat transfer coefficient value followed by $\mathrm{SiO}_{2}$ and $\mathrm{Cu}$. Therefore, the presence of DM nanoparticles in EG could greatly enhance the cooling of compact heat exchanger compared with other types of nanofluids. This is due to the highest thermal transport capacity of DM in nature. DM particles are often used as filler in mixtures for upgrading the performance of a matrix (composition of mixtures) as reported by Xie et al. [8] and Mohammed et al. [29]. Thus, it is reasonable to expect that the addition of DM nanoparticles in EG would lead to heat transfer enhancement about 9.1\% in the thermally developing region.

\subsection{Influence of Coolant Reynolds Number on Thermal Perfor-} mance of a CHE. Coolant Reynolds number plays vital role in determining the radiator's thermal performance. Engine might be overcooled or overheated if coolant Reynolds number is not properly controlled. The main function of a radiator is to ensure that engine is operating at optimum temperature by not only controlling the air Reynolds number but also the coolant Reynolds number. Although the coolant pump is usually driven by an engine, thermostat is also playing an important role to control the coolant Reynolds number [10]. This section presents the effect of coolant Reynolds number on the thermal performance of a CHE at a fixed air Reynolds number of 4000 as shown in Figure 5. The average heat transfer coefficient based on coolant side was increased with coolant Reynolds number. About 33\% and 31\% heat transfer enhancement are observed for pure EG and EG with 2\% DM nanoparticles, respectively, when coolant Reynolds number is increased from 5000 to 7000 . The magnitude of this property for all types of nanofluids is higher than that of a base fluid. The highest enhancement is found, when using DM nanofluid, and 3.3\% improvement of heat transfer has been achieved at 4000 and 7000 Reynolds number for air and coolant, respectively, compared to base fluid.

\subsection{Influence of Air Reynolds Number on Thermal Perfor-} mance of a CHE. In this section, the coolant Reynolds number is fixed at 6000, while the air Reynolds number is varied. With the increase in air Reynolds numbers, the heat transfer coefficient based on the air side is increased linearly with Reynolds number as shown in Figure 6. About 30\% and $31 \%$ heat transfer enhancement are observed for pure EG

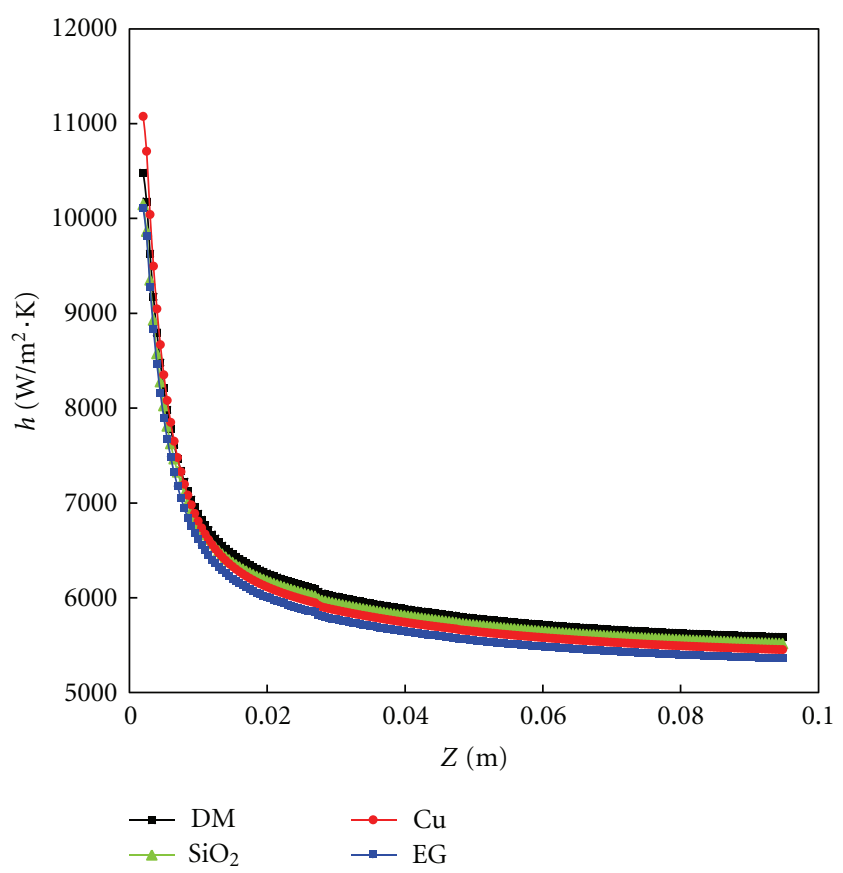

FIGURE 4: Variation of heat transfer coefficient along the length of the tube.

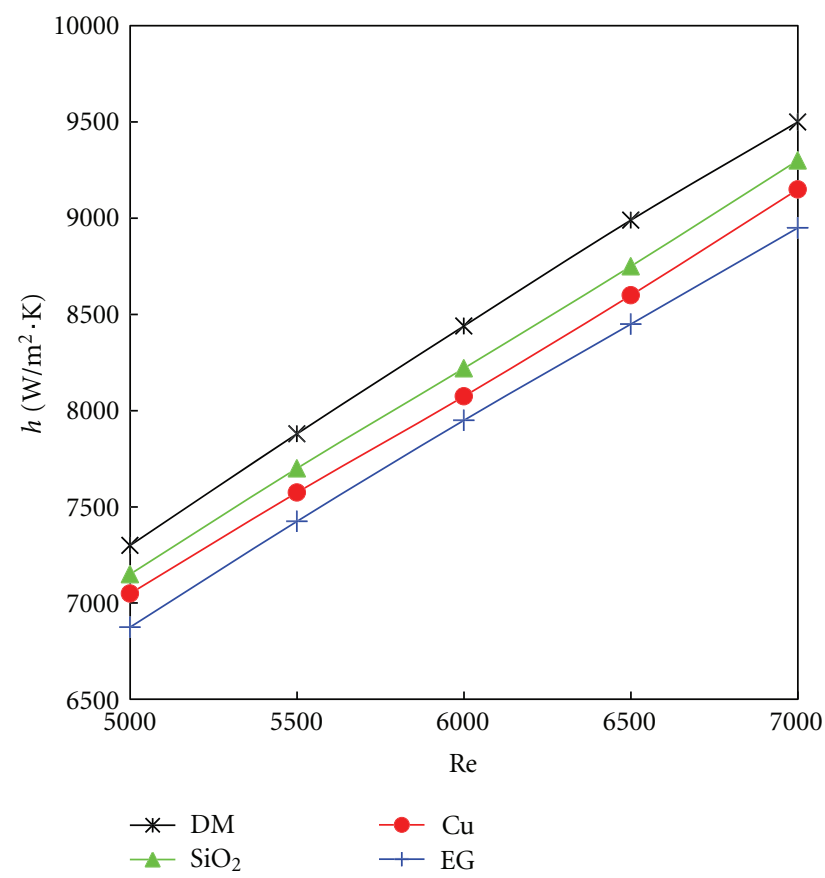

FIGURE 5: Variation of average coolant heat transfer coefficient against the coolant Reynolds number.

and EG with 2\% of DM nanoparticles, respectively, when air Reynolds number is increased from 4000 to 6000 . The average heat transfer coefficient is found proportional with air Reynolds number, and nanofluids generate higher heat transfer coefficient than that of base fluid, which shows the same scenario as illustrated in Figure 5. The highest enhancement 


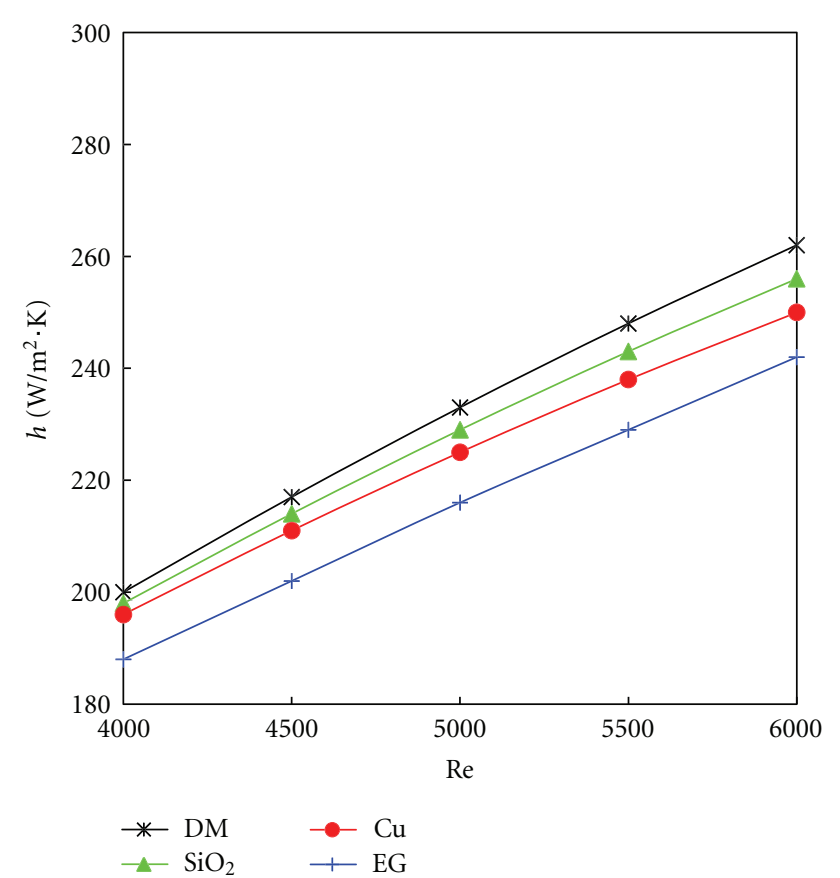

Figure 6: Variation of average air heat transfer coefficient against the air Reynolds number.

is still found, when imposing the DM nanofluid, as about $6.8 \%$ of heat transfer coefficient improvement can be achieved using DM particles in EG at 5000 and 6000 Reynolds number for air and coolant, respectively.

4.4. Coolant Pressure Drop and Pumping Power. The pressure distribution along the tube length for various nanofluids and pure EG at coolant Reynolds number of 6000 and air Reynolds number of 4000 is shown in Figure 7. Since the viscosity of nanofluids is larger than pure EG as indicated in Table 2, larger pressure drop is expected in a CHE operated with nanofluid-based coolants. Another reason that contributes to increase the pressure drop is the deposition of nanoparticle in EG, which is increasing the wall roughness, as reported by Murshed et al. [30], but this is not modeled in the present study. Therefore, larger pressure drop is expected in the nanofluid-based coolants. As depicted in Figure 7, it is noted that nanofluids containing $\mathrm{SiO}_{2}$ the highest value of pressure drop and are followed by DM-EG and Cu-EG. It is also found that $\mathrm{Cu}-\mathrm{EG}$ coolant has slight increase in pressure drop than pure EG coolant. The reason for this result is that Cu-EG has the lowest Prandtl number $(\mathrm{Pr}=5.6)$. The small difference in pressure drop between diamond-EG and $\mathrm{SiO}_{2}$-EG coolants which can be seen in Figure 7 is due to small differences in their Prandtl numbers, and $\mathrm{SiO}_{2}-\mathrm{H}_{2} \mathrm{O}$ yields the highest pressure drop across the flat tube due to its highest Prandtl number $(\operatorname{Pr}=6.8)$. Therefore, the pressure drop penalty is not only affected by the viscosity of nanofluids but also on the Prandtl number of nanofluids which need to be considered in nanofluids selection as a coolant for CHE. Apart from that, slight increment in pressure drop particularly for $\mathrm{Cu}-\mathrm{EG}$ coolant can be considered as one of the benefits of using

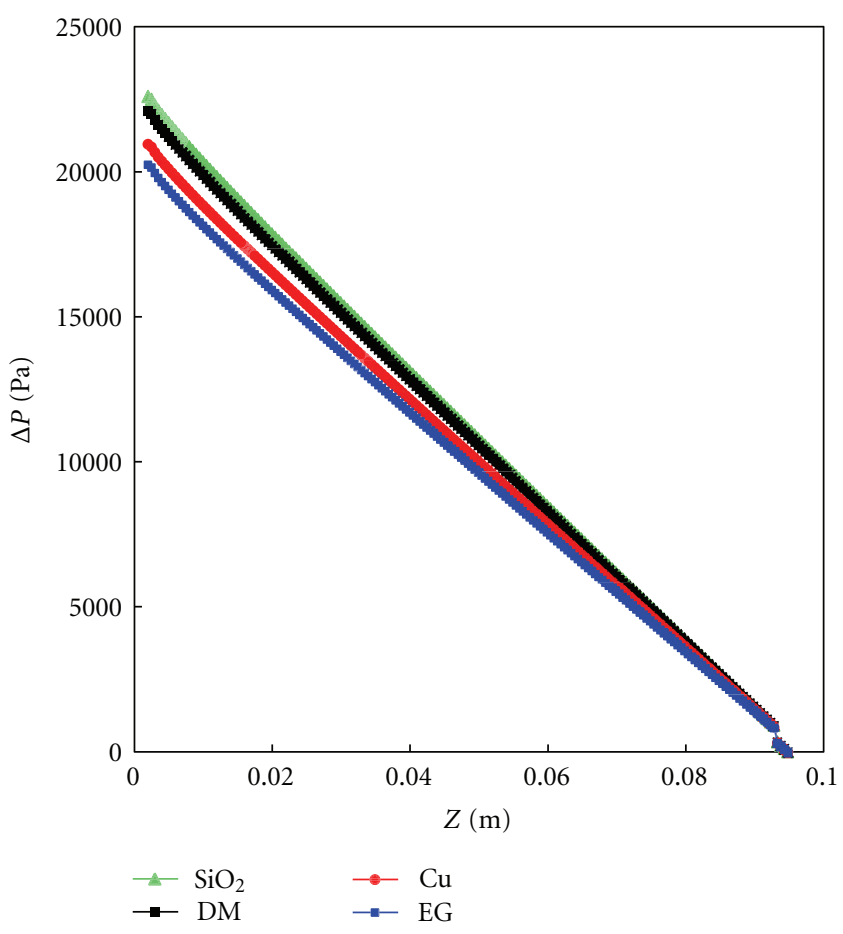

Figure 7: Pressure distribution along the tube length.

nanofluid in a CHE operations in order to achieve overall heat transfer enhancement with small pressure drop penalty.

Another important parameter in CHE operation is the coolant pumping power which relates to the pressure drop across the CHE required. The pumping power is used to drive the coolant in CHE operation. It is the product of the pressure drop, $\Delta P$, and volume flow rate, $Q$,

$$
\text { pumping power }=Q \Delta P \text {, }
$$

where $Q$ is defined as

$$
Q=(n \text { tube })(\mathrm{tW})(\mathrm{tH}) u_{\text {in }},
$$

where $n$ tube is the number of tubes, tW is the width of tube, tH is the height of tube, and $u_{\text {in }}$ is the inlet velocity of coolant.

The effect of nanofluids on the pumping power as a function of Reynolds number is shown in Figure 8 for various nanofluids and EG base fluid. The result reveals that as the Reynolds number increases, $\mathrm{SiO}_{2}$ requires the highest pumping power followed by $\mathrm{DM}, \mathrm{Cu}$, and EG alone. Since nanofluid yields extrapressure drop, a higher coolant pumping power is needed. The pumping power is calculated using (9). Calculated results indicate that about $18 \%$ increase in pumping power is observed for $\mathrm{SiO}_{2}$ at a coolant Reynolds number of 7000 compared to a base fluid. Increase in density increases pressure drop of flowing liquids. Adding particles in a base liquid increases the density of the fluid and augments pressure drop at a low percentage as observed in the present study. Similar results were reported by Ko et al. [31] and Duangthongsuk and Wongwises [32]. 


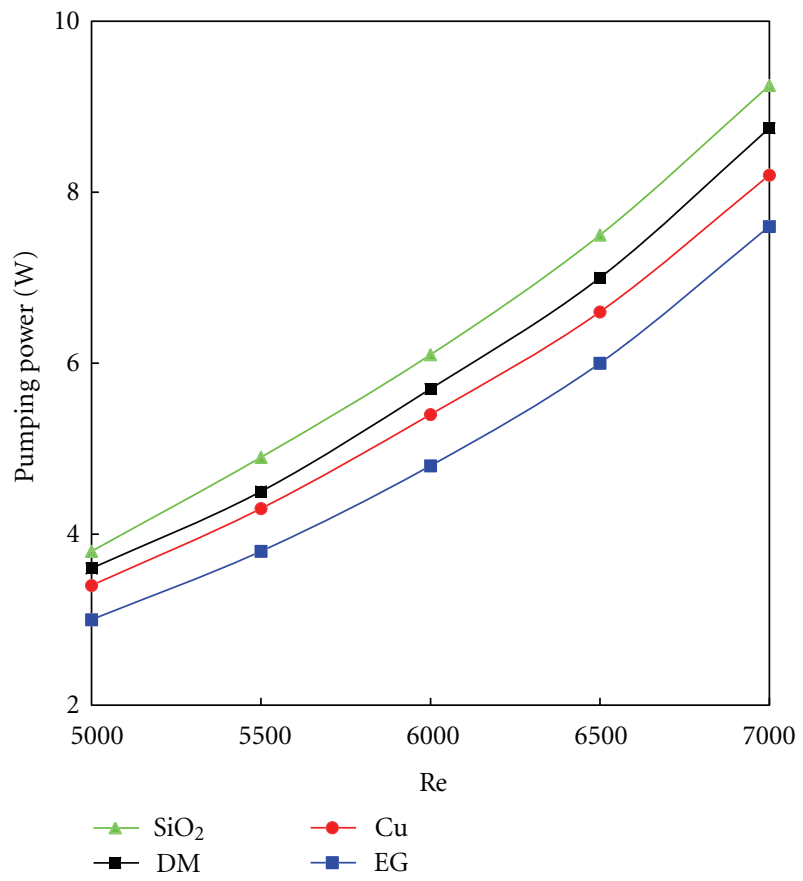

Figure 8: Pumping power of various nanofluids and EG at fixed coolant Reynolds number.

4.5. Shear Stress and Skin Friction Coefficient. Figure 9 illustrates how the shear stress on the tube wall varies with respect to the axial length. This run is for the EG and nanofluids at a Reynolds number of 6000. Since the hydrodynamic boundary layer's thickness is zero at the entrance of the tube, the wall shear stress is extremely large at $Z=0$. However, as the boundary layer develops, the wall shear stress diminishes rapidly until the constant values associated with the fully developed conditions are reached [26]. It can obviously be seen that for all types of nanofluids investigated, the presence of nanoparticles substantially increases the wall shear stress as compared with pure EG. Apart from pure EG-cooled $\mathrm{CHE}$, for all other cases examined, the least wall shear stress occurs in $\mathrm{Cu}-\mathrm{EG}$-cooled $\mathrm{CHE}$, while the highest corresponds to $\mathrm{SiO}_{2}-\mathrm{EG}$-cooled $\mathrm{CHE}$ followed by $\mathrm{DM}$, in trend with the variation in pressure drop, as discussed in Section 4.4. This also might be caused by the agglomeration of the nanoparticles which may give rise to particle deposition onto the tube wall and leads to rise the wall shear stress as reported by Ho et al. [33]. The highest wall shear stress is found for $\mathrm{SiO}_{2}$ nanofluid, which is $14 \%$ higher than that of the base fluid in the hydrodynamically developing region.

Figure 10 shows the variation of the local fanning skin friction coefficient, which is shown along the length of the tube for various nanofluids and also pure EG for the same inlet velocity. It is observed that the local skin friction coefficient for all types of nanofluids is larger than the EG, which is caused by a greater pressure drop across the flat tube. The computations were carried out for a uniform inlet velocity of $5.5 \mathrm{~m} / \mathrm{s}, 6.1 \mathrm{~m} / \mathrm{s}, 6.2 \mathrm{~m} / \mathrm{s}$, and $5.9 \mathrm{~m} / \mathrm{s}$ for a $\mathrm{EG}, \mathrm{DM}, \mathrm{SiO}_{2}$, and $\mathrm{Cu}$, respectively, corresponding to a Reynolds number of 6000. For all cases, the flow is hydrodynamically fully

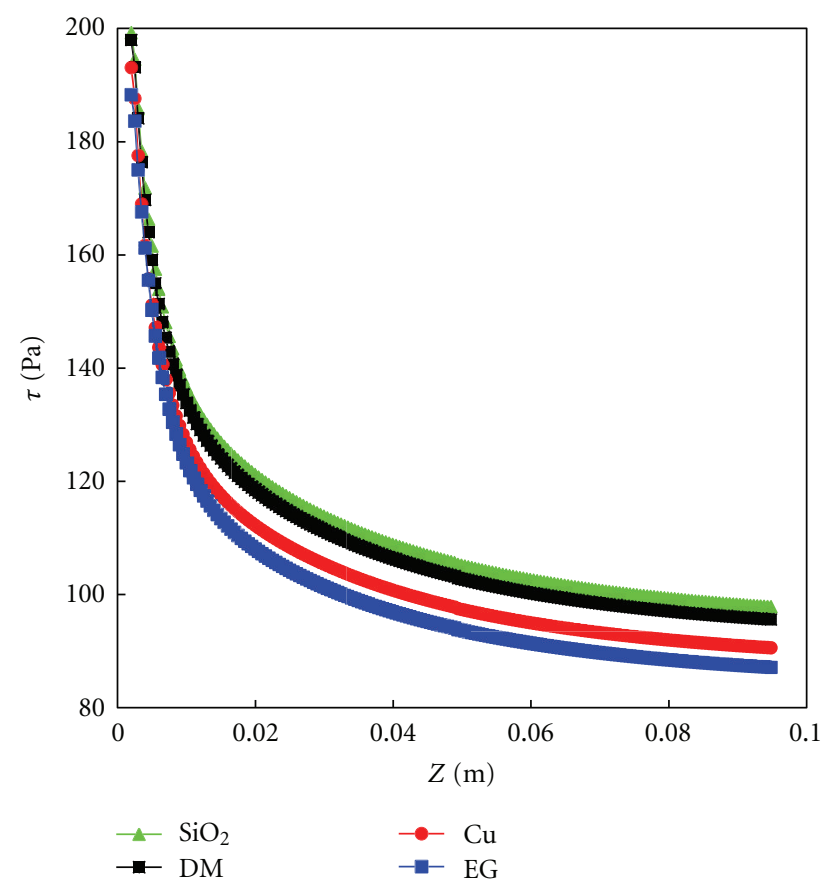

FIGURE 9: Variation of wall shear stress along the length of the tube.

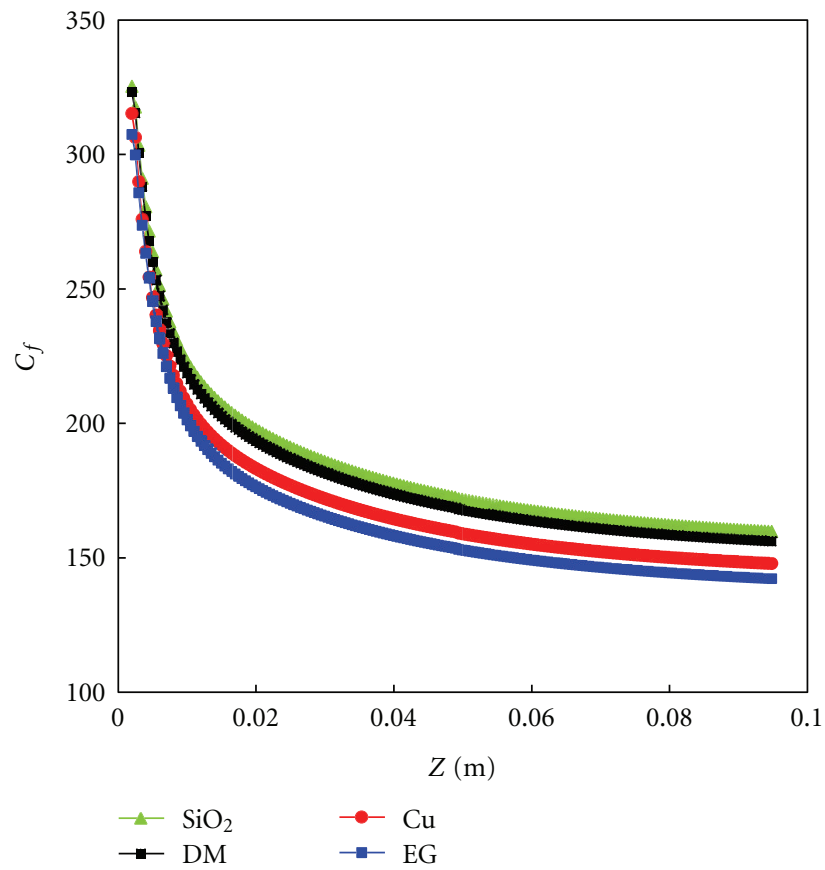

FIGURE 10: Variation of fanning skin friction coefficient along the length of the tube.

developed at $Z=0.08 \mathrm{~m}$. The fanning skin friction coefficient for $\mathrm{SiO}_{2}$ nanofluid is 1.13 times that of the base fluid in the developing region. For the current study, the skin friction coefficient is calculated using equation [34]

$$
C_{f}=\frac{\zeta_{w}}{1 / 2 \rho U_{\text {in }}^{2}},
$$

where $\zeta_{w}$ is the local wall shear stress of tube, $\rho$ is the coolant density, and $U_{\text {in }}$ is the inlet velocity of coolant. 


\section{Conclusions}

Numerical simulations on nanofluid flow and heat transfer characteristics in a CHE are reported in this study. The impacts of using different types of nanoparticles on both hydraulic and thermal of CHEs are comprehensively studied. Using a single-phase fluid assumption, the computed results for the average heat transfer coefficient for the air Reynolds number in the range of 4000-6000 agree well with the data available from Leong et al. [10]. Based on the presented results, the following conclusions can be drawn:

(i) the heat transfer coefficient for diamond nanofluid is $9.1 \%$ higher than that of the base fluid in the thermally developing region;

(ii) thermal performance of a CHE using nanofluid or EG coolant alone is increased with air and coolant Reynolds number;

(iii) the fanning skin friction coefficient for $\mathrm{SiO}_{2}$ nanofluid is 1.13 times that of the base fluid in the hydrodynamically developing region at an inlet velocity of $6.2 \mathrm{~m} / \mathrm{s}$;

(iv) additional $18 \%$ pumping power is needed for a $\mathrm{CHE}$ using $\mathrm{SiO}_{2}$ nanofluid at coolant Reynolds number of 7000 compared to a base fluid.

\section{Nomenclature}

A: $\quad$ Cross-sectional area, $\mathrm{m}^{2}$

$C_{f}: \quad$ Fanning skin friction coefficient

$C_{p}: \quad$ Specific heat, $\mathrm{J} / \mathrm{kg} \cdot \mathrm{K}$

CHEl: Compact heat exchanger length, $m$

CHEh: Compact heat exchanger height, $m$

CHEw: Compact heat exchanger width, $\mathrm{m}$

$D_{h}: \quad$ Hydraulic diameter, $\mathrm{m}$

fD: $\quad$ Distance between fins, $m$

fH: $\quad$ Fin height, $m$

fT: $\quad$ Fin thickness, $m$

fW: $\quad$ Fin width, $\mathrm{m}$

$h$ : $\quad$ Heat transfer coefficient, $\mathrm{W} / \mathrm{m}^{2} \cdot \mathrm{K}$

$\kappa: \quad$ Fluid thermal conductivity, $\mathrm{W} / \mathrm{m} \cdot \mathrm{K}$

$n: \quad$ Direction normal to the wall

$n$ tube: Number of tubes

$P_{\text {in }}: \quad$ Inlet pressure, $\mathrm{Pa}$

$P_{\text {out }}: \quad$ Outlet pressure, $\mathrm{Pa}$

Pr: $\quad$ Prandtl number

Q: $\quad$ Volume flow rate, $\mathrm{m}^{3} / \mathrm{s}$

Re: $\quad$ Reynolds number

$T_{a}$ : $\quad$ Air temperature, $\mathrm{K}$

$T: \quad$ Temperature, $\mathrm{K}$

$T_{c}$ : $\quad$ Coolant temperature, $\mathrm{K}$

$T_{\text {in }}$ : Fluid inlet temperature, $\mathrm{K}$

$T_{s}$ : $\quad$ Surface temperature, $\mathrm{K}$

tH: $\quad$ Tube height, $\mathrm{m}$

tL: $\quad$ Tube length, $m$

tW: $\quad$ Tube width, $\mathrm{m}$

u: $\quad$ Fluid velocity, $\mathrm{m} / \mathrm{s}$ $u_{\text {in }}: \quad$ Inlet fluid velocity, $\mathrm{m} / \mathrm{s}$

$x, y, z: 3 \mathrm{D}$ cartesian coordinates

$Z$ : $\quad$ Axial distance from the inlet, $m$.

Greek Symbols

$\varphi$ : Volume fraction of particles, $\%$

$\mu$ : Dynamic viscosity, $\mathrm{Ns} / \mathrm{m}^{2}$

$\rho:$ Density, $\mathrm{kg} / \mathrm{m}^{3}$

$\zeta$ : Shear stress, Pa.

\section{Subscripts}

bf: Base fluid

$f$ : Friction

$i$ : Inlet

$o$ : Outlet

p: Particles

$n f:$ Nanofluid

s: Solid

w: Wall.

\section{Acknowledgment}

The authors would like to sincerely thank the Ministry of Higher Education (MOHE) of Malaysia for the provision of a Grant with code no. 12012011ERGS to support this work.

\section{References}

[1] W. M. Kays and A. L. London, Compact Heat Exchanger, McGraw-Hill, USA, 3rd edition, 1984.

[2] S. U. S. Choi, "Enhancing thermal conductivity of fluids with nanoparticles," in Developments and Applications of NonNewtonian Flows, D. A. Siginer and H. P. Wang, Eds., FEDV.231/MD-V.66, pp. 99-105, ASME, New York, NY, USA, 1995.

[3] S. K. Das, N. Putra, P. Thiesen, and W. Roetzel, "Temperature dependence of thermal conductivity enhancement for nanofluids," Journal of Heat Transfer, vol. 125, no. 4, pp. 567$574,2003$.

[4] V. Trisaksri and S. Wongwises, "Critical review of heat transfer characteristics of nanofluids," Renewable and Sustainable Energy Reviews, vol. 11, no. 3, pp. 512-523, 2007.

[5] X. Q. Wang and A. S. Mujumdar, "Heat transfer characteristics of nanofluids: a review," International Journal of Thermal Sciences, vol. 46, no. 1, pp. 1-19, 2007.

[6] R. L. Webb, Principles of Enhanced Heat Transfer, John Wiley \& Sons, New York, NY, USA, 1993.

[7] X. Wang, X. Xu, and S. U.S. Choi, "Thermal conductivity of nanoparticle-fluid mixture," Journal of thermophysics and heat transfer, vol. 13, no. 4, pp. 474-480, 1999.

[8] H. Xie, J. Wang, T. Xi, Y. Liu, F. Ai, and Q. Wu, “Thermal conductivity enhancement of suspensions containing nanosized alumina particles," Journal of Applied Physics, vol. 91, no. 7, p. 4568, 2002.

[9] J. A. Eastman, S. U. S. Choi, S. Li, W. Yu, and L. J. Thompson, "Anomalously increased effective thermal conductivities of 
ethylene glycol-based nanofluids containing copper nanoparticles," Applied Physics Letters, vol. 78, no. 6, pp. 718-720, 2001.

[10] K. Y. Leong, R. Saidur, S. N. Kazi, and A. H. Mamun, "Performance investigation of an automotive car radiator operated with nanofluid-based coolants (nanofluid as a coolant in a radiator)," Applied Thermal Engineering, vol. 30, no. 17-18, pp. 2685-2692, 2010.

[11] B. Farajollahi, S. G. Etemad, and M. Hojjat, "Heat transfer of nanofluids in a shell and tube heat exchanger," International Journal of Heat and Mass Transfer, vol. 53, no. 1-3, pp. 12-17, 2010.

[12] R. S. Vajjha, D. K. Das, and P. K. Namburu, "Numerical study of fluid dynamic and heat transfer performance of $\mathrm{Al}_{2} \mathrm{O}_{3}$ and $\mathrm{CuO}$ nanofluids in the flat tubes of a radiator," International Journal of Heat and Fluid Flow, vol. 31, no. 4, pp. 613-621, 2010.

[13] D. G. Charyulu, G. Singh, and J. K. Sharma, "Performance evaluation of a radiator in a diesel engine - a case study," Applied Thermal Engineering, vol. 19, no. 6, pp. 625-639, 1999.

[14] M. N. Pantzali, A. A. Mouza, and S. V. Paras, "Investigating the efficacy of nanofluids as coolants in plate heat exchangers (PHE)," Chemical Engineering Science, vol. 64, no. 14, pp. 3290-3300, 2009.

[15] S. E. B. Maiga, S. J. Palm, C. T. Nguyen, G. Roy, and N. Galanis, "Heat transfer enhancement by using nanofluids in forced convection flows," International Journal of Heat and Fluid Flow, vol. 26, no. 4, pp. 530-546, 2005.

[16] V. Vasu, K. R. Krishna, and A. C. S. Kumar, "Application of nanofluids in thermal design of compact heat exchanger," The International Journal of Nanotechnology and Applications, vol. 2, pp. 75-87, 2008.

[17] A. P. Frass, Heat Exchanger Design, John Wiley \& Sons, New York, NY, USA, 2nd edition, 1989.

[18] S. U. S. Choi, Z. G. Zhang, and P. Keblinski, "Nanofluids," in Encyclopedia of Nanoscience and Nanotechnology, vol. 6, pp. 757-773, 2004.

[19] Y. Xuan and W. Roetzel, "Conceptions for heat transfer correlation of nanofluids," International Journal of Heat and Mass Transfer, vol. 43, no. 19, pp. 3701-3707, 2000.

[20] J. C. Maxwell, A Treatise on Electricity and Magnetism, Oxford University Press, Cambridge, UK, 2nd edition, 1904.

[21] A. Einstein, Investigations on the Theory of the Brownian Movement, Dover Publications, New York, NY, USA, 1956.

[22] A. Akbarinia and A. Behzadmehr, "Numerical study of laminar mixed convection of a nanofluid in horizontal curved tubes," Applied Thermal Engineering, vol. 27, no. 8-9, pp. 1327-1337, 2007.

[23] J. Lee and I. Mudawar, "Assessment of the effectiveness of nanofluids for single-phase and two-phase heat transfer in micro-channels," International Journal of Heat and Mass Transfer, vol. 50, no. 3-4, pp. 452-463, 2007.

[24] J. D. Anderson, Computational Fluid Dynamic: The Basics with Applications, McGraw-Hill, New York, NY, USA.

[25] K. W. Park and H. Y. Pak, "Flow and heat transfer characteristics in flat tubes of a radiator," Numerical Heat Transfer, Part A, vol. 41, no. 1, pp. 19-40, 2002.

[26] F. P. Incropera and D. P. DeWitt, Introduction to Heat Transfer, John Wiley \& Sons, New York, NY, USA, 3rd edition, 1996.

[27] S. V. Patankar, Numerical Heat Transfer and Fluid Flow, Hemisphere Inc., McGraw-Hill, New York, NY, USA, 1980.

[28] B. E. Launder and D. B. Spalding, Mathematical Models of Turbulence, Academic Press, New York, NY, USA.

[29] H. A. Mohammed, P. Gunnasegaran, and N. H. Shuaib, "Influence of various base nanofluids and substrate materials on heat transfer in trapezoidal microchannel heat sinks," International Communications in Heat and Mass Transfer, vol. 38, no. 2, pp. 194-201, 2011.

[30] S. M. S. Murshed, K. C. Leong, and C. Yang, "Thermophysical and electrokinetic properties of nanofluids-a critical review," Applied Thermal Engineering, vol. 28, no. 17-18, pp. 21092125, 2008.

[31] G. H. Ko, K. Heo, K. Lee et al., "An experimental study on the pressure drop of nanofluids containing carbon nanotubes in a horizontal tube," International Journal of Heat and Mass Transfer, vol. 50, no. 23-24, pp. 4749-4753, 2007.

[32] W. Duangthongsuk and S. Wongwises, "An experimental study on the heat transfer performance and pressure drop of $\mathrm{TiO}_{2}-$ water nanofluids flowing under a turbulent flow regime," International Journal of Heat and Mass Transfer, vol. 53, no. 1-3, pp. 334-344, 2010.

[33] C. J. Ho, L. C. Wei, and Z. W. Li, "An experimental investigation of forced convective cooling performance of a microchannel heat sink with $\mathrm{Al}_{2} \mathrm{O}_{3}$ /water nanofluid," Applied Thermal Engineering, vol. 30, no. 2-3, pp. 96-103, 2010.

[34] L. F. Moody, "Friction factors for pipe flow," Journal of Heat Transfer, vol. 66, no. 8, pp. 671-684, 1944. 

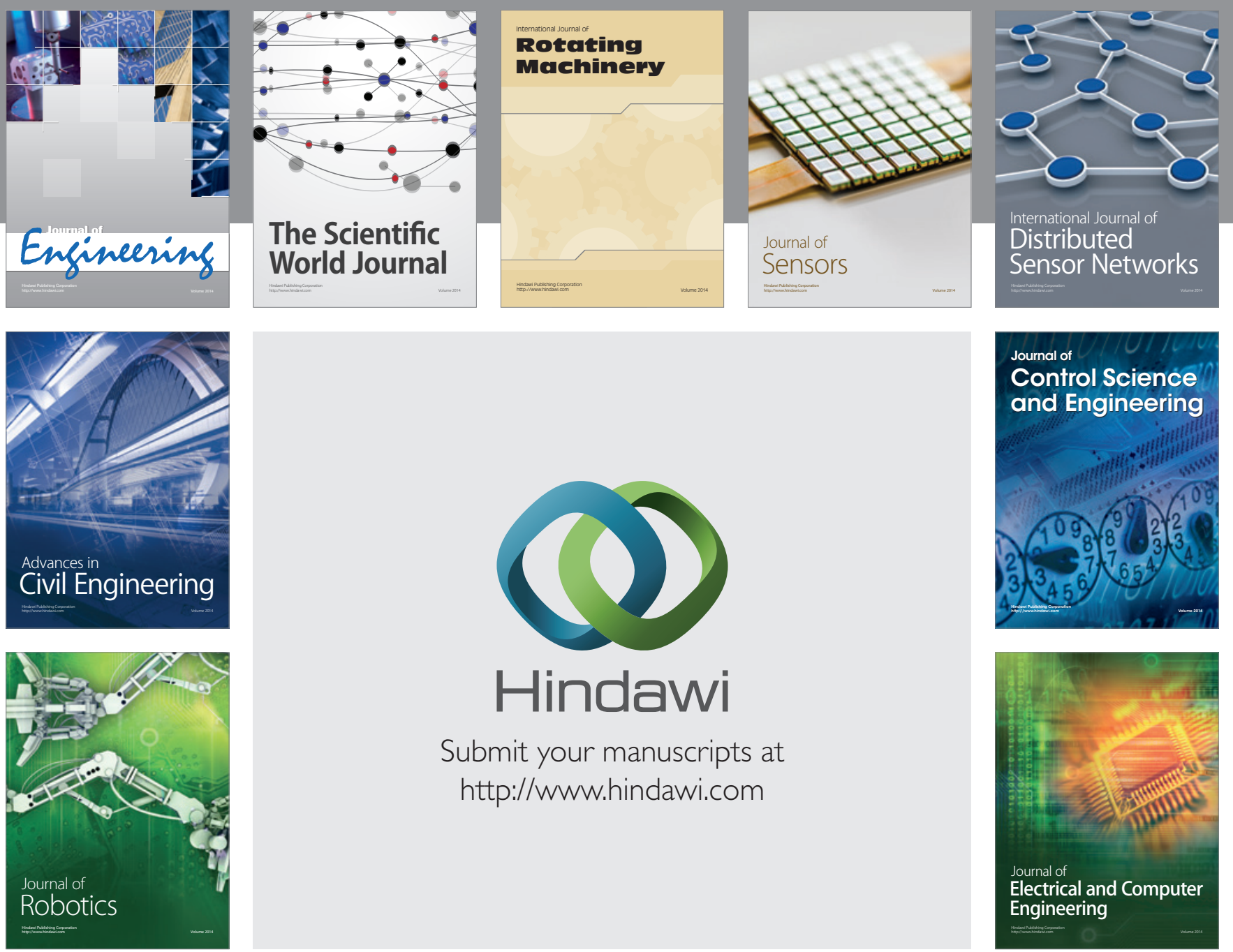

Submit your manuscripts at

http://www.hindawi.com
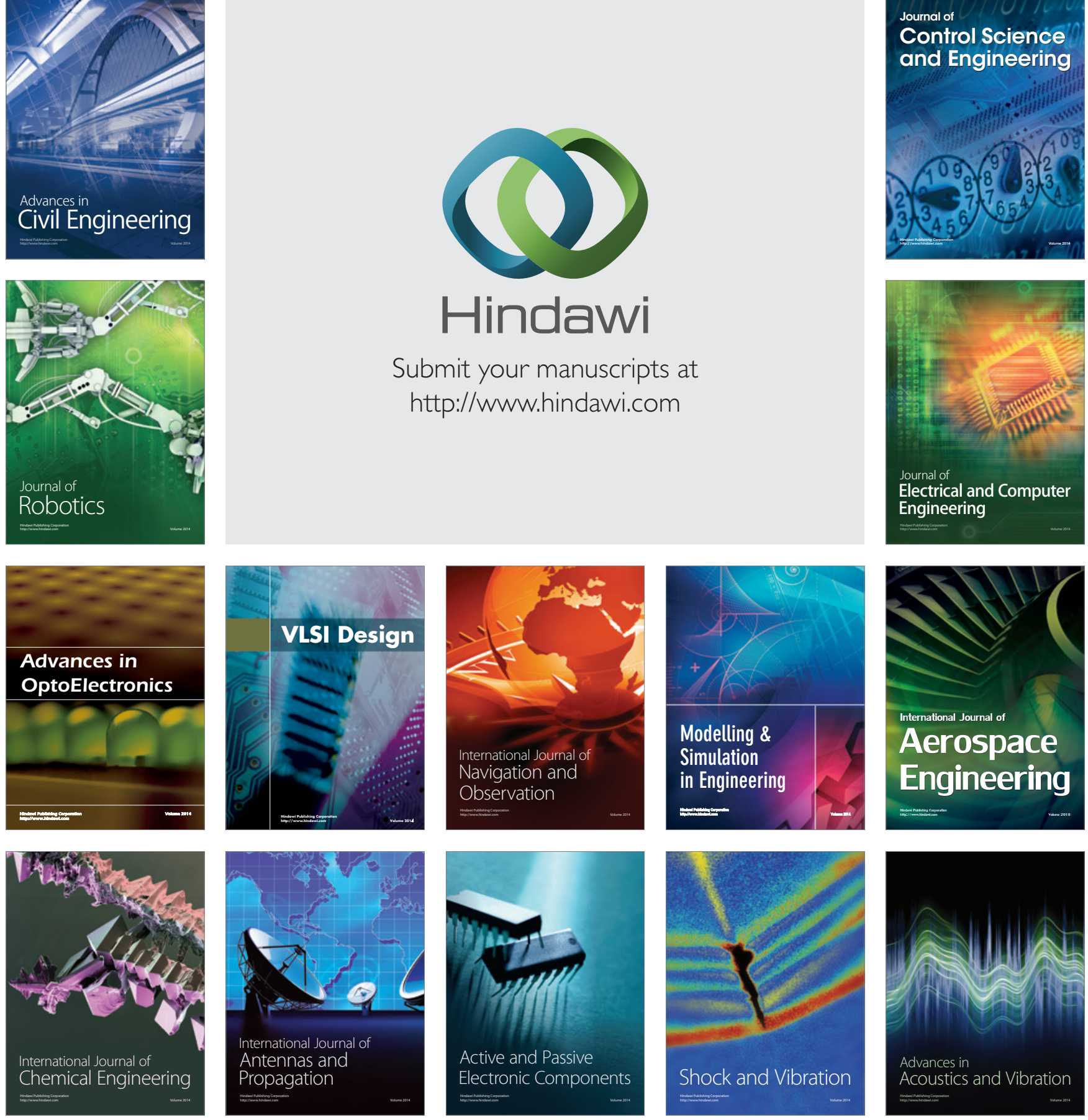